\title{
Building Sustainable Score (BSS)—A Hybrid Process Approach for Sustainable Building Assessment in China
}

\author{
Jiani Liu ${ }^{1}$, Grace K. C. Ding ${ }^{2}$, Bijan Samali ${ }^{1}$ \\ ${ }^{1}$ Faculty of Engineering \& IT, University of Technology Sydney, Sydney, Australia; ${ }^{2}$ Faculty of Design, Architecture and Building, \\ University of Technology Sydney, Sydney, Australia. \\ Email: Jiani.Liu-1@student.uts.edu.au
}

Received August 2013

\begin{abstract}
Sustainable building in China has gained attention both domestically and abroad. Despite the fast increase in sustainable assessment tools developed locally or adopted from overseas, there are still criticisms about the current situation of weak implementation and lack of comprehensive consideration. The lack of consideration of economic and social aspects or building performance on whole building life cycle all lead to departure from the true meaning of sustainable development. And lack of participation on the part of stakeholders makes it too theoretical to be carried out. This research aims to develop a model to address this problem. This research started with review of current sustainable assessment tools applied in China. As the assessment indicators have clear regional disparities, and almost no current tool considers all three pillars of environmental, economic and social in building life cycle. An industry survey was therefore designed for generation of indicators at different building stages, and personal interviews relevant to different occupation in building industry were conducted to complement the questionnaire survey. After that, the model Building Sustainable Score (BSS) was developed based on the stakeholders' participation. Finally, the model is verified by a case study.
\end{abstract}

Keywords: Building Sustainability; Hybrid Process Approach; LCA; AHP

\section{Introduction}

Buildings are one of the largest energy consumers in any industrialized country [1]. According to the report from Netherland Consulate in China [2], half of the new buildings worldwide will be built in China by 2015. By then approximately $40 \%$ of China's total energy consumption, $50 \%$ of concrete and $30 \%$ of steel, globally, will be consumed by the construction market in China. Therefore, sustainable buildings and the sustainable assessment tools have attracted much attention from the government both locally and nationally. In the past decades, several international sustainable assessment tools have been adopted and used in the Chinese construction market such as Leadership in Energy and Environmental Design (LEED) from the US, Comprehensive Assessment System for Building Environment Efficiency (CASSBE) from Japan and BRE Environmental Assessment Method (BREEAM) from the UK.

International green building assessment tools were useful to provide information on evaluating environmental performance of buildings in China. However, these tools have been developed as country specific and even though they have been modified to suit buildings in China, they may not have been used effectively and sufficiently. Gradually, tools were developed in China to fill the gap. In 2003, the Tsinghua University developed and issued a 'Green Olympic Building Assessment System (GOBAS) for the construction of buildings for Olympic games. The tool was adopted by Beijing Municipal Construction Commission as one of the Beijing's local green building standards [3]. Following GOBAS, a national three star green building evaluation standard was launched in China in 2006 called the 'Evaluation Standards for Green Buildings (ESGB).

With the development of local building assessment tools, there are still some criticisms of these tools as most of them consider environmental factors only, and only a few take economic and social factors into consideration [4]. Further criticisms about the effectiveness of building assessment methods state that they typically assess a building as a completed product and seldom consider impacts at different stages of a building cycle [5]. Environmental, economic and social criteria will have different impacts at various stages of a development and hence assessing building performance at different stages becomes important and necessary. Despite the fact that some research has focused on one or several of the building phases, 
none of them has considered all the stages from life cycle perspective [6-8]. Impacts during the life cycle of a project are highly inter-dependent, as one phase can influence one or more of the other phases. Each phase in a building life cycle plays an important role in achieving the goal of sustainability for a project. Besides, an overall rating score to assess a building's performance is hard to meet the requirements of all stake holders, as the definition of building performance varies according to different interest groups involved in building development [9]. In such cases, it is ideal to integrate social, environmental and economic factors at each stage of sustainability assessment in the decision-making process [10].

In order to fill this gap, this research is conducted to establish a model which assesses the building sustainable performance of the three pillars at all the stages in building life cycle. A questionnaire survey and personal interviews were used for data collection. With the survey, an assessment model based on building process approach (BPA) was established in this paper to aid decision making.

The objectives of this paper are as follows:

- Identifying the sustainable assessment indicators related to building processes.

- Establishing Building Sustainable Score (BSS) model based on building process approach (BPA).

\section{Research Method}

In order to achieve the goal of sustainability, all the phases during the building life cycle should be taken into consideration when the sustainability performance of a construction project is examined. In that case, life cycle analysis (LCA) and life cycle costing (LCC) are adopted in this research to assess environmental and economic factors whilst value score is used for the social factor. The entire building life cycle performance, building stages and hence the major activities in each phase, are taken into consideration. The building life cycle for the research has been divided into four stages of inception and design, construction, operation, and demolition.

At each stage, assessment indicators in conjunction with activities were identified using an industry questionnaire survey and semi-structured interviews. An online industry survey was conducted in February 2012 followed by 20 interviewees for deeper discussion. With this survey, an assessment model based on building process approach (BPA) is established in this paper to aid decision making.

\section{Data Collection and Analysis}

An industry survey was conducted to identify key indicators for assessment at different stages in a building life cycle. After conducting a pilot study with industry practitioners, an industry wide questionnaire survey was con- ducted online between February and May 2012. A total of 479 responses were collected. A follow-up semistructured personal interview with industry practitioners was also conducted in Guangdong Province for deeper investigation of the issues between May and June 2012.

Participants in this questionnaire survey were developers, design consultants, contractors, government agencies, academics and others. Others included lawyers, property managers, secretaries and construction workers. These six groups are highly relevant to the green building research and their opinion on sustainable assessment tools will contribute a lot to this research. Among those participants, 30.3\% have more than 20 years of work experience, $49.1 \%$ had 6 - 20 years and the rest had less than 5 years of work experience. Among these participants, about $56 \%$ of the them thought the current trend in green buildings in China is just starting and is developing slowly, $26 \%$ of the participants thought it has not started yet, $16 \%$ thought it has started and is developing fast and $2 \%$ thought it is almost at a mature stage but still behind the western countries. Compared with current literature about China's green building situation, as the views were not as optimistic as portrayed. Though the green building has started since the last century, they have not received enough attention from the public. As for the solution to this situation, "developing an assessment system" and "establishing a complete legal system" become their first choice.

In order to establish an assessment model, the indicators were identified from a literature review. In this survey, participants were asked to rank the relevant indicators based on their experience and knowledge. The Relative Importance Index (RII) was adopted to analyze the results. The indicators chosen were based on their relative importance. Table 1 shows the ranking of the indicators from the questionnaire survey.

After that, semi-structured interviews were conducted to further explore the relevance and importance of indicators at each stage.

\section{Model Development}

Based on the data analysis from the questionnaire survey and personal interviews, the indictors for each stage were developed. The conceptual model has been established as follows:

Based on the conceptual model (Figure 1), a mathematics model based on building process approach (BPA) is established to aid decision making. The assessment model consists of five sub-models, each of which reflects sustainability performance of a building phase. Each submodel will analyze the building performance in accordance with the environmental, economic and social aspects of building activities at each stage. 
Table 1. Indicators for assessing the buildings' sustainable impacts.

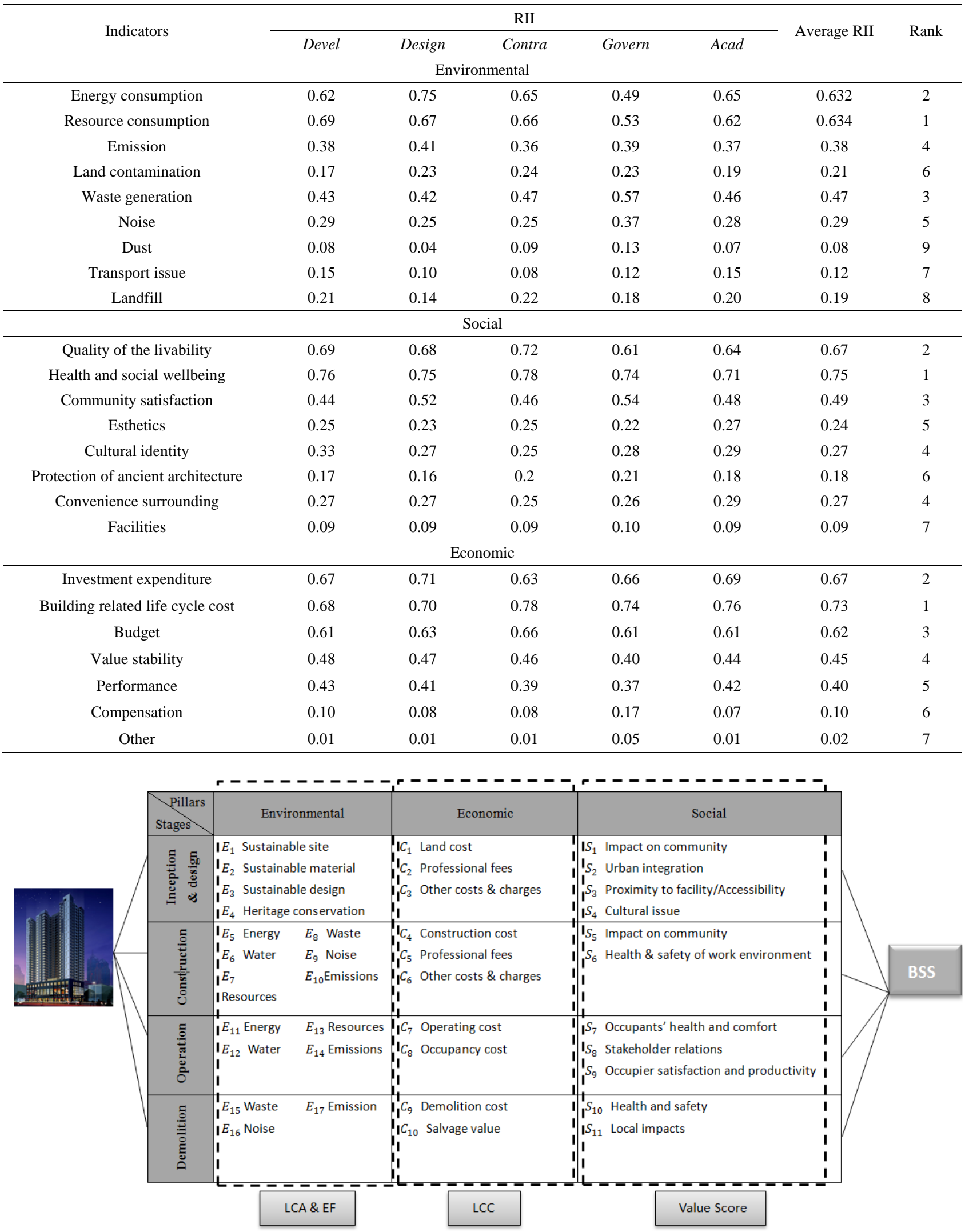

Figure 1. Conceptual model. 
Building Sustainable Score (BSS) is a score for the four stages and it is a step function which assumes different values at different stages of a project life cycle. To generate the weighting of indicators, analytic hierarchy process (AHP) is adopted. Weighting is needed to present the preference of some indicators against others when combining the indicators in the model. There are many ways to generate weighting, subjective ones and objective ones [11]. The reason for choosing AHP in this research is that it takes into consideration the decision makers' concerns and experts' experiences, which are considered essential for the purpose of evaluating the weightings. Another method which allows the decision maker to provide expert judgment on the relative importance of the indicators is Delphi. But it is very time consuming as it needs two or more rounds to generate consensus of opinions [11].

Based on the above discussion, the BSS model is established as follows:

$$
\mathrm{BSS}=\sum_{\mathrm{i}=1}^{\mathrm{n}} \mathrm{W}_{\mathrm{I}} \mathrm{S}_{\mathrm{I}}
$$

$\mathrm{S}_{\mathrm{I}}$ represents the sustainable score at each stage-inception, design, construction, operation and demolition.

$\mathrm{W}_{\mathrm{I}}$ represents the weight of each stage in sustainable performance.

$$
\mathrm{S}_{\mathrm{I}}=\mathrm{f}\left\{\mathrm{E}_{\mathrm{nI}}, \mathrm{E}_{\mathrm{cI},} \mathrm{S}_{\mathrm{oI}}\right\}
$$

At each stage, the sustainable score consists of environmental score, economic score and social score.

$E_{n I}$ represent the environmental score at one stage

$\mathrm{E}_{\mathrm{CI}}$ represent the economic score at one stage

$\mathrm{S}_{\mathrm{oI}}$ represent the social score at one stage

$$
\mathrm{E}_{\mathrm{nI}}=\sum_{\mathrm{i}=1}^{\mathrm{n}} \mathrm{w}_{\mathrm{i}} \mathrm{E}_{\mathrm{nI}}^{\mathrm{i}}
$$

$E_{n I}^{i}$ represent the environmental score of an indicator $\mathrm{w}_{\mathrm{i}}$ represent the weighting for each indicator

AHP method is used to generate weightings of the indicators based on group decision. Suppose there are "k" experts filling questionnaires to assign weightings to "n" indicators, the pair-wise comparison matrix is as follows (based on the research of Yang [11]):
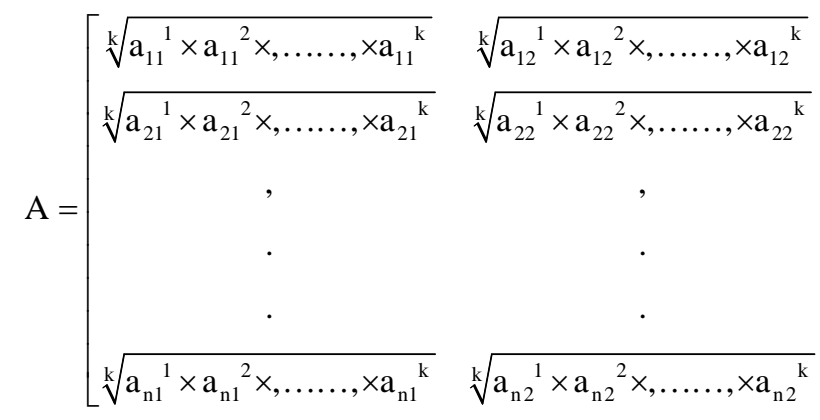

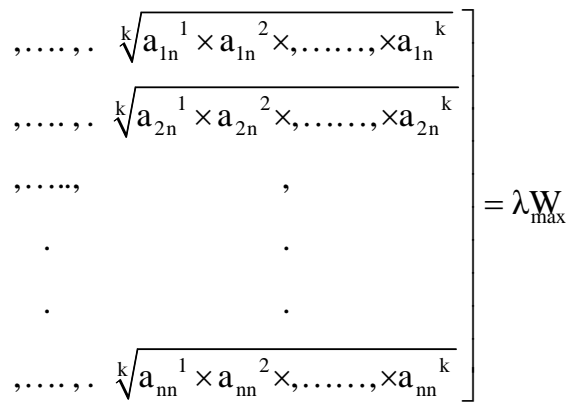

$\lambda_{\max }$ is the maximum eigen value of a comparison matrix.

$\mathrm{W}$ is the corresponding eigenvector, the components in $\mathrm{W}$ are the weightings for each of the indicators.

This model assesses environmental, economic and social performance at each stage in a building life cycle. It combines quantitative and qualitative analysis. It quantifies the indicators as much as possible which offers a more systematic evaluation. Besides, the weighting system can offer opportunities for interaction with the stakeholders. So it is more adaptable to local and personal issues.

\section{Conclusions}

This paper presented the building sustainable score (BSS) as an assessment model for a building process approach. An industry survey and semi-structured personal interviews were conducted for data collection, and in order to generate the assessment indicators at different phases of a building life cycle for the model development. AHP method is adopted to generate the weightings for the indicators. A case study will be conducted for model verification as part of further research.

Key findings in this research include the following:

- Generating assessment indicators for the three pillars. As discussed above, the indicators in assessment model have strong regional disparities and choosing the adaptable local indicators is the basis of this research. Based on the industry survey and personal interviews, a series of indicators are generated for the BSS model.

- Establishing the building sustainable score model to aid decision making. The BSS model reveals the sustainability performance at various stages of the development so that resources can be dedicated on the stage that has the most significant impacts on overall improvements. Besides, different interest groups have different requirements of building performance and getting the satisfactory performance will help the stakeholder to make better decisions. 


\section{REFERENCES}

[1] S. Junnila, A. Horvath and A. A. Goggemos, "Life-Cycle Assessment of Office Buildings in Europe and the United States,” Journal of Infrastructure Systems, Vol. 12, No. 1, 2006, pp. 10-17.

http://dx.doi.org/10.1061/(ASCE)1076-0342(2006)12:1(10)

[2] Netherland Consulate in China, "ChinaTop Sector Energy: Sustainable Building Opportunities for Dutch companies," 2012. http://china.nlambassade.org/

[3] Green Olympic Building Research Center, "Green Olympic Building Assessment System,” China Construction Industrial Press, Beijing, 2003.

[4] L. Y. Shen, M. Wu and J. Y. Wang, "A Model for Assessing the Feasibility of Construction Project in Contribution to the Attainment of Sustainable Development," Journal of Construction Research, Vol. 3, No. 3, 2002, pp. 255-269. http://dx.doi.org/10.1142/S1609945102000151

[5] E. Kaatz, D. Root, P. A. Bowen, and R. C. Hill, “Advancing Key Outcomes of Sustainability Building Assessment," Building Research and Information, Vol. 34, No. 4, 2006, pp. 308-320. http://dx.doi.org/10.1080/09613210600724608

[6] M. M. Bilec, R. J. Ries and H. S. Matthews, "Life-Cycle Assessment Modeling of Construction Processes for Buildings,” Infrastructure System, Vol. 16, No. 3, 2010, pp. 199-205.

http://dx.doi.org/10.1061/(ASCE)IS.1943-555X.0000022
[7] C. Scheuer, G. A. Keoleian and P. Reppe, "Life Cycle Energy and Environmental Performance of a New University Building: Modeling Challenges and Design Implications,” Energy and Buildings, Vol. 35, No. 10, 2003, pp. 1049-1064. http://dx.doi.org/10.1016/S0378-7788(03)00066-5

[8] A. Guggemos and A. Horvath, "Strategies of Extended Producer Responsibility for Buildings,” Infrastructure System, Vol. 9, No. 2, 2003, pp. 65-74. http://dx.doi.org/10.1061/(ASCE)1076-0342(2003)9:2(65)

[9] R. J. Cole, "Emerging Trend in Building Environmental Assessment Methods,” Build Research and Information, Vol. 26, 1998, pp. 3-16.

http://dx.doi.org/10.1080/096132198370065

[10] P. O. Akadiri, P. O. Olomolaiye and E. A. Chinyio, "Multi-Criteria Evaluation Model for the Selection of Sustainable Materials for Building Projects," Automation in Construction, Vol. 30, 2013, pp. 113-125. http://dx.doi.org/10.1016/j.autcon.2012.10.004

[11] Y. Yang, B. Li and R. Yao, “A Method of Identifying and Weighting Indicators of Energy Efficiency Assessment in Chinese Residential Buildings,” Energy Policy, Vol. 38, No. 12, 2010, pp. 7687-7697. http://dx.doi.org/10.1016/j.enpol.2010.08.018 